\title{
Aspectos da Propagação de Persea hilldenovi Kosterm. (LAURACEAE)
}

\author{
Claudimar Sidnei Fior', Lia Rosane Rodrigues ${ }^{2}$, \\ Ari Delmo Nilson ${ }^{1} \&$ Cristina Leonhardt ${ }^{1}$
}

\begin{abstract}
Resumo
(Aspectos da propagação de Persea willdenovii Kosterm. (Lauraceae)) Persea willdenovii é uma espécie arbórea cuja ocorrência foi registrada desde o estado de Minas Gerais até o Rio Grande do Sul, principalmente nas formações de altitude. $P$. willdenovii encontra-se ameaçada de extinção no Rio Grande do Sul, principalmente devido ao amplo emprego fitoterápico. Para identificar e caracterizar aspectos relevantes na produção de mudas de $P$. willdenovii, foi conduzida uma série de experimentos, visando à propagação através de sementes e de partes vegetativas. Nos experimentos visando à propagação sexuada, a emergência ocorreu após um período mínimo de 34 dias. Também foi observada associação da germinação a um período de declínio da temperatura ambiente. Nos experimentos visando à propagação vegetativa, $P$. willdenovii apresentou limitações, principalmente a restrição do potencial morfogênico aos tecidos juvenis, a presença de contaminação de origem endógena e o alto índice de oxidação dos tecidos. A propagação vegetativa foi viabilizada a partir de tecidos de plântulas germinadas in vitro. Assim, foi possível registrar a resposta da espécie às estratégias mais comuns de propagação, identificar os problemas a serem resolvidos para viabilizar a multiplicação, além de gerar 300 novas plantas a partir de duas matrizes.
\end{abstract}

Palavras-chave: Persea pyrifolia, recurso genético, semente, substrato, morfogênese.

\section{Abstract}

(Aspects of Persea willdenovii Kosterm. (Lauraceae) propagation) Persea willdenovii is a woody plant recorded growing in some Brazilian States, from Minas Gerais to Rio Grande do Sul, mainly in higher altitudes. $P$. willdenovii in Rio Grande do Sul is in danger of extinction, as the local people use this plant for phytotherapic purposes. To identify important aspects of $P$. willdenovii propagation, tests where conducted with seeds and vegetative structures. The germination of seed took a minimum of 34 days, associated with a decline of the temperature. $P$. willdenovii showed limitations to the vegetative propagation: morphogenic potential restricted to the juvenile tissues, presence of endogenous contamination, and high level of phenolic oxidation. Vegetative propagation was only possible with the use of juvenile tissues of plantlets germinated in vitro. By means of this sequence of tests it was possible to record responses to current propagation techniques, to identify problems to be solved in order to regenerate new plants, and to obtain 300 new plants from only two specimens.

Key words: Persea pyrifolia, genetic resource, seed, substrate, morphogenesis.

\section{INTRODUÇÃO}

A família Lauraceae tem distribuição nas Américas, Ásia Tropical, Austrália, Madagascar e, com menor expressão, no sul da África. É representada por 50 gêneros e 2500 espécies, que variam desde árvores ou arbustos até trepadeiras parasitas (Cassytha) (Quinet \& Andreata 2002).

No Brasil, ocorrem 19 gêneros e 390 espécies, em sua maior parte, habitando as florestas pluviais, restingas e cerrados. Em inventários florísticos e fitossociológicos realizados em áreas de florestas preservadas da porção sudeste-sul do país, a família das lauráceas vem sendo apontada como uma das mais representativas, tanto em número de indivíduos quanto em riqueza de táxons, o que corrobora a hipótese de que esta região seja um dos principais centros de diversidade deste grupo (Quinet \& Andreata 2002).

\footnotetext{
Artigo recebido em 04/2005. Aceito para publicação em 04/2006

${ }^{1}$ Jardim Botânico, Fundação Zoobotânica do Rio Grande do Sul. Av. Salvador França, 1427, 90690-000, Porto Alegre, RS, Brasil.csfior@ufrgs.br

${ }^{2}$ Departamento de Botânica, Instituto de Biociências, Universidade Federal do Rio Grande do Sul. Av. Bento Gonçalves, 9500, Prédio 43423, Sala 204, 91501-970, Porto Alegre, RS, Brasil.
} 
Espécies de Ocotea e Nectandra, conhecidas popularmente como canelas, loureiros ou embuias, destacaram-se desde o início da colonização sul-americana, quando foram exploradas para emprego na construção naval e moveleira de luxo. Em função desta importância econômica, associada à inexistência de programas efetivos de manejo florestal, a maior parte das espécies de lauráceas encontra-se em perigo de extinção (Quinet \& Andreata 2002).

No Rio Grande do Sul, foi registrada a ocorrência dos gêneros Nectandra, Ocotea, Aniba, Aiouea, Cinnamomum, Endichleria, Cryptocarya, Phoebe, Licaria e Persea (Pedralli 1983; Reitz et al.1988). Do gênero Persea, são citadas apenas duas espécies nativas, ambas pertencentes ao subgênero Eriodaphne, P. venosa Nees \& Mart. ex Nees e $P$. willdenovii Kosterm., anteriormente denominada $P$. pyrifolia Nees \& Mart. ex Nees. A denominação $P$. pyrifolia, criada em 1833, foi trocada em 1969, porque é um homônimo posterior da espécie asiática $P$. pyrifolia (D. Don) Spreng., descrita em 1827 (Kostermans 1969).

Persea americana Miller, o abacateiro, ocorre cultivado no Rio Grande do Sul como frutífera de pequena expressão comercial. Apesar do amplo potencial para exportação na entressafra de países grande consumidores do fruto, seu cultivo é limitado por questões climáticas e, principalmente, pela suscetibilidade ao fungo de solo Phytophthora cinnamomi Rands. Neste contexto, salientase a importância da preservação e do estudo das espécies nativas do subgênero Eriodaphne, como fontes de variabilidade genética já confirmadas para $P$. americana (Pliego-Alfaro \& Bergh 1992), principalmente para a constituição de porta-enxertos.

A progressiva diminuição das áreas de floresta pluvial, por alterações ambientais de origem antrópica, está intensificando a erosão genética e a ameaça de extinção destas espécies da flora do Rio Grande do Sul. Em P. americana, a erosão genética foi registrada até mesmo no principal centro de diversidade, o México (Barrientos-Pliego \& López-López 1998).

$$
\text { Persea willdenovii, conhecida }
$$
popularmente como abacateiro-do-mato, maçaranduba, pau-de-andrade ou canela-rosa, é uma espécie arbórea que ocorre desde o estado de Minas Gerais até o Rio Grande do Sul, principalmente nas formações de altitude (Quinet \& Andreata 2002). Os raros exemplares de $P$. willdenovii encontrados no Rio Grande do Sul estão sob constante ameaça de depredação devido, principalmente, ao amplo emprego na medicina popular. As técnicas caseiras de preparo de fitoterápicos a partir de casca, ramos e folhas são bastante difundidas, mas a pesquisa das propriedades farmacológicas do gênero Persea ainda está em seu estádio inicial (Scora \& Scora 2000; Caballero-George et al. 2001; Fraga et al. 2001; Adeyemi et al. 2002; Gallagher et al. 2003). Por isso, o desenvolvimento de técnicas que viabilizem a propagação de $P$. willdenovii pode assegurar sua preservação e estudo. Porém, não foram encontrados trabalhos detalhados direcionados à propagação desta espécie.

Para identificar e caracterizar aspectos relevantes na produção de mudas de $P$. willdenovii, foi conduzida uma série de experimentos, visando à propagação, tanto através de sementes quanto através de partes vegetativas.

\section{Material e Métodos \\ Material vegetal}

No período de agosto de 2000 a dezembro de 2004, realizaram-se coletas de ramos e frutos de duas plantas de $P$. willdenovii, uma localizada no município de Machadinho (Fig. 1a) e outra no município de Bom Jesus, ambos no Rio Grande do Sul. Depois de coletado, o material foi envolvido em papel umedecido e acondicionado em embalagem plástica. Em laboratório, foi realizada a despolpa manual dos frutos e lavagem das sementes em água corrente. Transcorreram, no máximo, $48 \mathrm{~h}$ desde a coleta até a instalação dos experimentos. 


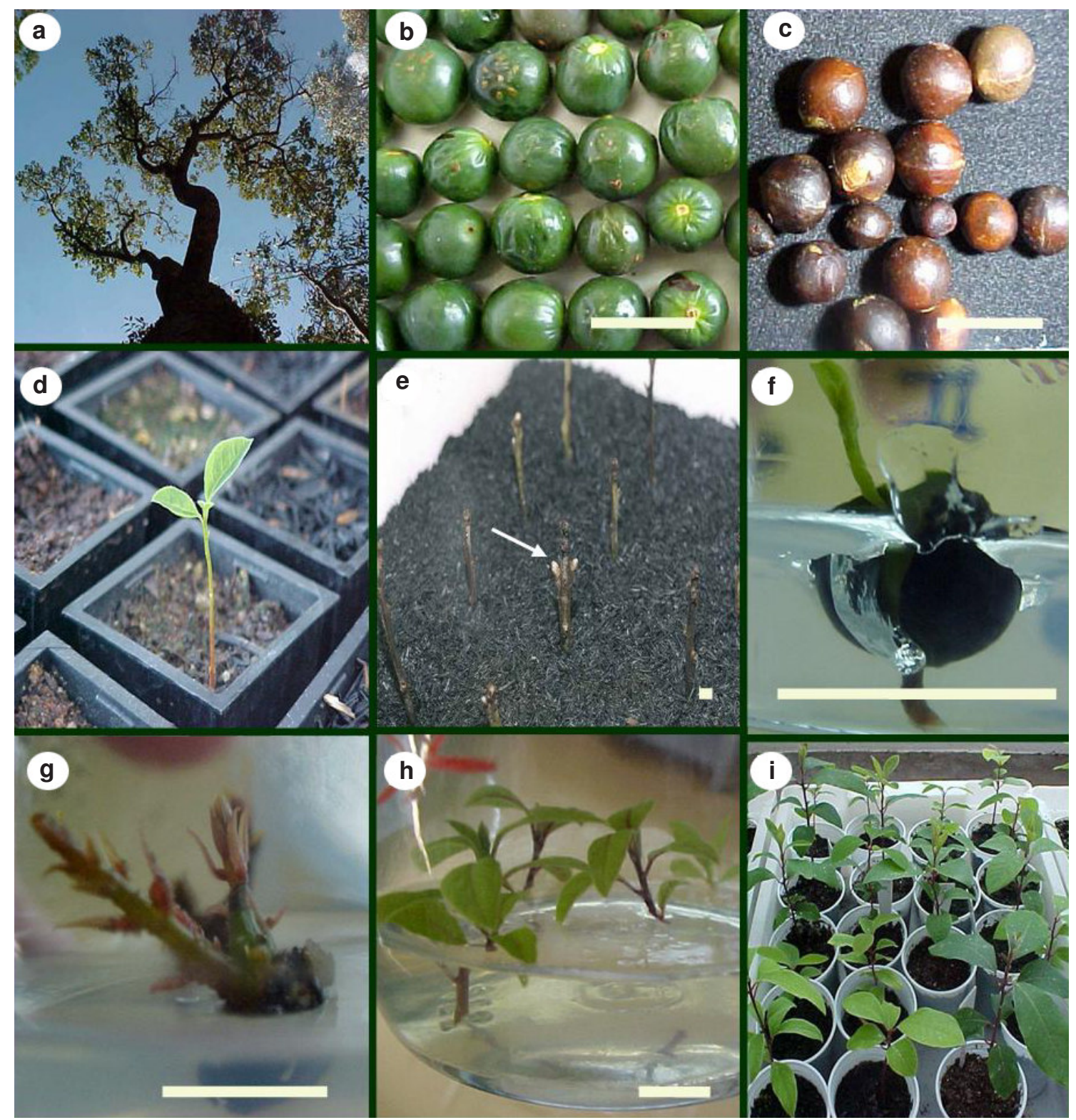

Figura 1 - Persea willdenovi - a. planta adulta; b. frutos maduros; c. sementes recém-despolpadas; d. plântula germinada em casa de vegetação; e. emissão de brotações em estaca apical; f. plântula germinada in vitro; g. organogênese em segmentos nodais; $h$. ápices caulinares em meio para enraizamento; i. mudas em desenvolvimento (Barras $=1 \mathrm{~cm}$ ).

Após a despolpa dos frutos, verificou-se que, aproximadamente, $30 \%$ das sementes estavam infestadas por larvas de insetos da família Curculionidae. Por isso, foi realizada uma triagem, eliminando-se as danificadas.

O pequeno número de plantas adultas e o seu intenso estado de depredação reduziram a quantidade de indivíduos amostrados, por isso, alguns experimentos têm um número baixo de repetições.

\section{Experimentos visando à propagação por sementes}

\subsection{Semeadura sob diferentes regimes térmicos}

Sementes coletadas em abril de 2002, da planta do município de Machadinho, foram imersas por 10 minutos em hipoclorito de sódio $2 \%$ i.a., enxaguadas e secas ao ar sobre papel filtro. De 10 amostras, foram tomadas as medidas transversal e longitudinal de frutos 
inteiros e das sementes. O peso de mil sementes foi determinado conforme as Regras para Análise de Sementes (Brasil 1992). O teor de água das sementes foi determinado pelo método da estufa a $105^{\circ} \mathrm{C} \pm 3^{\circ} \mathrm{C}$, durante $24 \mathrm{~h}$, utilizando-se duas repetições de 10 sementes.

A semeadura foi feita em caixas "gerbox" contendo $200 \mathrm{~g}$ de areia e $20 \mathrm{ml}$ de água destilada. Durante todo o teste foi mantida a umidade através de reposições, em iguais quantidades por parcela, sempre que necessário. Os tratamentos constituíram-se de regimes térmicos conduzidos em germinadores $(\mathrm{UR}=90-95 \%): 20^{\circ} \mathrm{C}$ constante; $25^{\circ} \mathrm{C}$ constante; e 20 e $30^{\circ} \mathrm{C}$ alternado $\left(20^{\circ} \mathrm{C}\right.$ por 16 $\mathrm{h}$ e $30^{\circ} \mathrm{C}$ por $8 \mathrm{~h}$ ). O delineamento foi completamente casualizado com quatro repetições de 15 sementes $(3$ × 4 x $15=180$ sementes). A cada três ou quatro dias, foi avaliado o percentual de sementes germinadas, considerando como critério de germinação as plântulas normais (Brasil, 1992). O tempo médio de germinação foi calculado de acordo com a fórmula de Silva \& Nakagawa (1995):

Sendo:

$$
T M=\frac{G 1 T 1+G 2 T 2 \ldots+G i T i}{G 1+G 2 \ldots+G i}
$$

$\mathrm{TM}=$ tempo para atingir a germinação máxima.

$\mathrm{G}_{1}$ até $\mathrm{Gi}=$ percentual de germinação ocorrida a cada dia.

$\mathrm{T}_{1}$ até $\mathrm{Ti}=$ tempo (dias).

Para que os valores de germinação apresentassem distribuição normal, foi utilizada a transformação Asen(Raiz x). Os dados foram submetidos à análise da variância (ANOVA).

\subsection{Semeadura em diferentes substratos}

Sementes da mesma procedência do Experimento 1.1, processadas da mesma forma, foram submetidas, simultaneamente, à semeadura em "plugs" de polietileno preto com volume $66 \mathrm{ml}$, apoiados em suporte plástico. Os tratamentos constituíram-se de três substratos: $\mathrm{CO}=$ composto orgânico, obtido da decomposição de resíduos de poda e varreduras do parque do JB, peneirado em malha de $3 \mathrm{~mm}$; CA = casca de arroz, carbonizada de acordo com Kämpf (2000); e PC = pó-de-coco comercial Golden Mix $P M^{\circledR}$ da empresa Amafibra. O material vegetal foi mantido sobre bancada em casa de vegetação, sem controle de temperatura e sob intensidade luminosa natural de, aproximadamente, 15000 Lux. Procedeu-se a irrigação a cada dois dias, por sistema de aspersão, em quantidade suficiente para umedecer todo o substrato. A emergência (visualização do epicótilo acima do nível do substrato) e o desenvolvimento das plântulas (altura da parte aérea) foram avaliados quinzenalmente, no período de abril a outubro de 2002, compreendendo o período do outono, inverno e início da primavera. As temperaturas médias do período foram obtidas de CPTEC (2003).

$\mathrm{O}$ delineamento experimental foi em blocos casualizados, com quatro repetições de 48 a 52 sementes, totalizando 588 sementes. Os dados foram submetidos à ANOVA e as médias foram comparadas pelo teste de Duncan (5\%).

Amostras dos três substratos foram analisadas no Laboratório de Análises de Substrato do JB/FZB-RS, quanto à densidade úmida (em $\mathrm{kg} \mathrm{m}^{-3}$ ), ao $\mathrm{pH}$ (determinado em água na proporção de 1:2,5 v:v) e à salinidade (em g. $1^{-1}$, calculada a partir da condutividade elétrica determinada em água, na proporção de 1:10 p:v), de acordo com o método VDLUFA (Röber \& Schaller 1985).

\subsection{Semeadura in vitro}

Sementes $(n=13)$ da mesma procedência dos Experimentos 1.1 e 1.2, processadas da mesma forma, foram submetidas à: lavagem com escova e detergente em água corrente até a remoção completa da polpa aderida à testa; enxágüe em água corrente por 15 minutos; imersão em etanol $70 \%$ por 1 minuto; imersão em hipoclorito de sódio $1 \%$ i. a. por 15 minutos; e triplo enxágüe em $\mathrm{H}_{2} \mathrm{O}$ deionizada autoclavada, em câmara de fluxo laminar. Cada semente foi estabelecida em um frasco (altura $8 \mathrm{~cm}$ e diâmetro $6 \mathrm{~cm}$ ) contendo 
$35 \mathrm{ml}$ de meio MS (Murashige \& Skoog 1962) acrescido de 30 g. $l^{-1}$ de sacarose, 7 g. $l^{-1}$ de ágar Merck $^{\circledR}, 1,3$ mg..$^{-1}$ de benzilaminopurina (BAP) e 0,05 mg. $1^{-1}$ de ácido indolbutírico (AIB), pH 5,8 . A transferência para meio fresco de igual constituição foi feita a cada 40 dias. O material foi mantido em sala de crescimento sob condições controladas (temperatura $25 \pm 2^{\circ} \mathrm{C}$ e fotoperíodo de $16 \mathrm{~h}$ a $2500 \mathrm{Lux}$ ) e avaliado durante 10 meses.

\subsection{Semeadura in vitro com ácido giberélico}

Em um teste adicional, sementes coletadas em abril de 2003, da planta do município de Bom Jesus, foram submetidas à desinfestação, conforme descrito no item 1.3, e determinação do teor de água, conforme descrito no item 1.1. Cem sementes inteiras (20 por tratamento) e 20 embriões destacados dos cotilédones (cinco por tratamento) foram individualmente estabelecidos em tubos de ensaio contendo 8 $\mathrm{ml}$ de meio MS acrescido de $2 \mathrm{~g} . \mathrm{l}^{-1}$ carvão ativado, 23 g..$^{-1}$ de sacarose e 10 g..$^{-1}$ de ágar Vetec $^{\circledR}, \mathrm{pH} 5,8$. Concentrações crescentes de ácido giberélico $\left(\mathrm{GA}_{3}\right)\left(0 ; 0,5 ; 1 ; 2 ;\right.$ e $\left.4 \mathrm{mg} . \mathrm{l}^{-1}\right)$ no meio de cultivo constituíram os tratamentos. O material foi mantido em sala de crescimento sob condições controladas, listadas no item 1.3, e avaliado durante 10 meses.

\section{Experimentos visando à propagação vegetativa in vivo}

\subsection{Enxertia}

Ramos apicais da planta do município de Machadinho (diâmetro 5-10 mm) foram desfolhados, limpos com escova e detergente em água corrente, e enxertados, por meio de garfagem em fenda cheia, em 10 plantas de $P$. venosa, geradas in vitro no trabalho de Rodrigues et al. (1998). Cada enxerto foi amarrado ao porta-enxerto com filme PVC (Jacomino et al. 2000) e coberto com pequeno saco plástico, preso por um arame flexível abaixo do ponto de enxertia. As plantas foram protegidas por tela do tipo "sombrite" com 50\% de sombreamento e mantidas em local abrigado de ventos e do sol da tarde. A retirada da proteção plástica e da amarra de filme plástico foi realizada de acordo com a aparência do material, com base na experiência dos autores com a enxertia de $P$. americana.

\subsection{Estaquia de ramos}

Ramos da planta do município de Machadinho (diâmetro 4-13 mm) foram lavados, desinfestados e cortados para obtenção de estacas com $\sim 14 \mathrm{~cm}$ de comprimento, contendo duas a três folhas. Para a realização dos tratamentos, a base de cada estaca foi cortada em bisel e os tecidos expostos foram pressionados contra misturas de talco industrial e AIB em concentrações crescentes (0, 1000, 3000 e 6000 ppm). Esta operação foi organizada em dois blocos, um deles com estacas com diâmetro de até $9 \mathrm{~mm}$ e outro com diâmetro maior que $9 \mathrm{~mm}$.

As estacas foram instaladas em bandejas plásticas de 40 × 40 × $20 \mathrm{~cm}$ contendo casca de arroz carbonizada umedecida. O material foi mantido sob nebulização intermitente sobre uma bancada de concreto em casa de vegetação, sem controle de temperatura. Para prevenir o ataque de fungos, foram feitas aplicações semanais intercaladas dos fungicidas Benomyl (Benlate ${ }^{\circledR}$ ) a 1 g. $^{-1}$ e Mancozeb $\left(\right.$ Manzate $^{\circledR}$ ) a 0,8 g. l $^{-1}$. O delineamento experimental foi em blocos casualizados com diferente número de repetições por tratamento, totalizando 120 estacas.

\section{Experimentos visando à propagação vegetativa in vitro}

\subsection{Propagação vegetativa a partir de tecidos juvenis}

Neste experimento, todos os cultivos foram conduzidos em frascos de vidro com altura $8 \mathrm{~cm}$ e diâmetro $6 \mathrm{~cm}$, contendo $35 \mathrm{ml}$ dos meios: A) MS acrescido de $30 \mathrm{~g} . \mathrm{l}^{-1} \mathrm{de}$ sacarose, 7 g. $l^{-1}$ de ágar Merck ${ }^{\circledR}, 1,3$ mg. $l^{-1}$ de BAP e 0,05 mg..$^{-1}$ de AIB; B) MS com $67 \%$ dos macro e micronutrientes e $200 \%$ das 
vitaminas, acrescido de $0,001 \mathrm{mg} . \mathrm{l}^{-1}$ de ANA, $0,05 \mathrm{mg} . \mathrm{l}^{-1}$ de BAP, $20 \mathrm{~g} . \mathrm{l}^{-1}$ de sacarose e 7 g. $1^{-1}$ de ágar Merck ${ }^{\circledR}$; C) MS com $50 \%$ dos macronutrientes e do ferro e $100 \%$ dos micronutrientes e das vitaminas, acrescido de $0,05 \mathrm{mg} . \mathrm{l}^{-1}$ de AIB e 1,3 mg. $\mathrm{l}^{-1}$ de BAP, 30 g. $1^{-1}$ de sacarose e 10 g..$^{-1}$ de ágar Vetec ${ }^{\circledR} ;$ D) MS acrescido de $30 \mathrm{~g}$ sacarose e 10 g. $\mathrm{l}^{-1}$ de carragenina; e E) MS acrescido de 30 g..$^{-1}$ de sacarose, $1 \mathrm{mg} . \mathrm{l}^{-1}$ de AIB e $10 \mathrm{~g} . \mathrm{l}^{-1}$ de ágar Vetec $^{\circledR}$. O pH dos meios foi corrigido para 5,8 antes da autoclavagem. A constituição dos meios foi estabelecida com base em testes preliminares.

Sementes da planta do município de Machadinho foram beneficiadas e desinfestadas, conforme descrito no item 1.3, e estabelecidas em meio A, em condições estéreis. As sementes foram mantidas em sala de crescimento sob condições controladas, listadas no item 1.3 , e transferidas para meio A fresco a cada 40 dias. Após a germinação, os caulículos das 4 plântulas germinadas ( 6 $\mathrm{cm}$ de altura e com 4 a 7 folhas) foram cortados junto aos cotilédones e seccionados para a separação de segmentos nodais e do ápice caulinar. Os explantes oriundos da plântula de cada semente foram estabelecidos em um mesmo frasco de cultivo, em meio de indução B. Após 42 dias, as brotações foram separadas dos explantes originais e transferidas para meio de multiplicação C. Nestas etapas, não foram comparados tratamentos e, sim, testada a resposta de $P$. willdenovii ao mesmo procedimento demonstrado em $P$. venosa por Rodrigues et al. (1998).

Após a multiplicação, um total de 185 brotações foram seccionadas uniformemente e distribuídas em tratamentos com concentrações crescentes de $\operatorname{BAP}(0 ; 0,3 ; 0,6$; 0,$9 ; 1,2 ;$ e $\left.1,5 \mathrm{mg} . \mathrm{l}^{-1}\right)$, em meio D. Ao final de 28 dias, foi avaliado o número de brotações por explante. As brotações foram individualizadas e transferidas para meio de enraizamento E. Após 112 dias, as plantas desenvolvidas e enraizadas foram transferidas para bandejas plásticas de $40 \times 25 \mathrm{~cm}$, contendo 51 de casca de arroz carbonizada, visando à aclimatização em casa de vegetação, sem controle de temperatura, sob nebulização intermitente, regulada para manter a umidade relativa do ar próxima a $100 \%$.

Os dados foram submetidos à análise estatística descritiva, à ANOVA e as médias foram comparadas pelo teste de Duncan (5\%).

\subsection{Propagação vegetativa in vitro a partir de tecidos não-juvenis}

Ramos apicais da planta do município de Machadinho foram lavados e cortados para obtenção de explantes. Este material foi submetido à desinfestação, conforme descrito em 1.3, intercalada por imersão em solução aquosa do fungicida "Benomyl" a 1 g. $\mathrm{l}^{-1}$. Em câmara de fluxo laminar, segmentos nodais, ápices caulinares e discos foliares foram estabelecidos em meios de cultivo básico MS, com variações quanto ao tipo de fitorreguladores e a concentração de carvão ativado. $\mathrm{O}$ material foi cultivado em sala de crescimento, sob condições controladas, e avaliado após 30 dias.

Brotações e calos das estacas do experimento 2.2. também foram removidos, desinfestados e estabelecidos em dois meios de cultivo: um visando a indução à organogênese direta (MS acrescido de 0,25 mg..$^{-1}$ de BAP, 30 g..$^{-1}$ de sacarose e 7 g..$^{-1}$ de ágar Merck ${ }^{\circledR}$, $\mathrm{pH} 5,8$ ) e o outro à embriogênese somática [meio Gamborg et al. (1968) acrescido de $2 \mathrm{mg}$ de ácido 2,4-diclorofenoxiacético (2,4-D), 0,5 mg..$^{-1}$ de BAP, 90 g..$^{-1}$ de sacarose e 2,5 g..$^{-1}$ Phytagel, pH 6,4]. Foram utilizados 8 calos e 5 brotações por tratamento, totalizando 13 frascos. O material foi mantido em sala de crescimento, sob condições controladas, e avaliado após 30 dias.

\section{Resultados}

\subsection{Semeadura sob diferentes regimes térmicos}

No momento da coleta, os frutos de $P$. willdenovii apresentavam exocarpo túrgido e brilhante e polpa firme; no dia seguinte, mostravam exocarpo enrugado e polpa macia. 
O teor de água das sementes de $P$. willdenovii foi de $49,7 \%$ e o peso de mil sementes igual a 137,3 g. Os diâmetros transversal e longitudinal foram equivalentes, tanto no fruto $(71,0 \pm 5,5 \mathrm{~mm})$ quanto na semente $(63,7 \pm 5,1 \mathrm{~mm})$ (Figs. $1 \mathrm{~b}$ e $1 \mathrm{c}$ ).

O início da germinação ocorreu entre 34 e 48 dias e a germinação transcorreu por 46 a 67 dias. Não houve diferença significativa entre os tratamentos (Tab. 1).

\subsection{Semeadura em diferentes substratos}

A emergência de plântulas em casa de vegetação foi bastante superior à observada no experimento 1.1: o percentual médio de emergência foi de $50,64 \%$ e as primeiras plântulas começaram a emergir aos 42 dias após a semeadura (Figs. 1d e 2a).

A emergência iniciou mais rapidamente em composto orgânico, tanto que, aos 100 dias, o percentual de plântulas emergidas era significativamente superior neste tratamento. Porém, aos 200 dias, esta diferença foi compensada, e os tratamentos não diferiram quanto ao percentual de emergência (Tab. 2). A Figura $2 b$ mostra que o período subseqüente à semeadura coincidiu com o início do declínio da temperatura, em função da estação do ano.


Figura 2 - Gráficos representativos da emergência de $P$. willdenovii em três substratos: $\mathrm{PC}=$ pó de coco Golden Mix tipo $P M^{\circledR}, \mathrm{CA}=$ casca de arroz carbonizada, e $\mathrm{CO}=$ composto orgânico produzido a partir de resíduos de podas e varreduras do parque do Jardim Botânico de Porto Alegre. a. Percentual de emergência de plântulas aos 200 dias após a semeadura. b. Média de emergência de plântulas de $P$. willdenovii (barra) e temperaturas médias do ambiente (linha), durante 200 dias de avaliação, após a semeadura. Fonte das temperaturas médias CPTEC (2003).

Tabela 1 - Comportamento germinativo de Persea willdenovii coletada no município de Machadinho, RS, submetida à semeadura em três regimes térmicos.

\begin{tabular}{|c|c|c|c|c|}
\hline \multirow[t]{2}{*}{ Regime Térmico } & \multirow[t]{2}{*}{ Germinação (\%) } & \multicolumn{3}{|c|}{ Germinação (em dias) } \\
\hline & & Início & Tempo Médio & Período Total \\
\hline $20^{\circ} \mathrm{C}$ constantes & 15,0 & 34 & 63 & 101 \\
\hline $25^{\circ} \mathrm{C}$ constantes & 11,6 & 46 & 66 & 92 \\
\hline $20-30^{\circ} \mathrm{C}$ alternados & 20,0 & 48 & 74 & 101 \\
\hline Média Geral & 15,5 & 43 & 68 & 98 \\
\hline $\mathrm{Pr}>\mathrm{F}$ & 0,3988 & - & 0,5634 & - \\
\hline CV\% & 29 & - & 16 & - \\
\hline Transformação & Asen (Raiz) & - & - & - \\
\hline
\end{tabular}


Tabela 2 - Características básicas dos três substratos testados; percentual de emergência e altura da parte aérea das plântulas de Persea willdenovii, 200 dias após a semeadura nos substratos: CO = composto orgânico do JB/FZB-RS, $\mathrm{CA}=$ casca de arroz carbonizada e $\mathrm{PC}=$ pó-de-coco Golden Mix $P M^{\circledR}$.

\begin{tabular}{|c|c|c|c|c|c|}
\hline \multirow[t]{2}{*}{ Substratos } & \multicolumn{3}{|c|}{ Características dos substratos } & \multirow[t]{2}{*}{ Germinação (\%) } & \multirow{2}{*}{$\begin{array}{l}\text { Altura da parte } \\
\text { aérea das } \\
\text { plântulas (cm) }\end{array}$} \\
\hline & $\begin{array}{l}\text { Densidade } \\
\text { úmida }\left(\mathbf{k g ~ m}^{-3}\right)\end{array}$ & pH & Salinidade (g.L $\left.{ }^{-1}\right)$ & & \\
\hline $\mathrm{CO}$ & 912 & 6,8 & 1,38 & 48,42 & $4,99 \mathrm{~b}$ \\
\hline $\mathrm{CA}$ & 261 & 7,3 & 0,70 & 48,43 & $4,67 \mathrm{c}$ \\
\hline $\mathrm{PC}$ & 322 & 6,3 & 0,50 & 55,05 & 5,31 a \\
\hline Média Geral & - & - & - & 50,64 & 4,99 \\
\hline $\operatorname{Pr}>\mathrm{F}$ & - & - & - & 0,292 & 0,001 \\
\hline $\mathrm{CV} \%$ & - & - & - & 12 & 30 \\
\hline
\end{tabular}

Médias seguidas de letras diferentes, na coluna, são significativamente diferentes pelo teste de Duncan 5\%.

O desenvolvimento das plântulas nos diferentes substratos foi comparado, após 200 dias da semeadura, através da medida da parte aérea de cada planta e houve diferença significativa entre os tratamentos (Tab. 2).

\subsection{Semeadura in vitro}

A semeadura in vitro não viabilizou um percentual de germinação maior do que os obtidos in vivo. Apenas quatro das 13 sementes da planta de Machadinho germinaram: a primeira, aos quatro meses ( 137 dias; Fig. 1f), a segunda, aos sete meses ( 213 dias), a terceira e a quarta, aos nove meses ( 247 dias). Neste caso, o período em que transcorreu a germinação foi bem posterior ao observado nos experimentos 1.1 e 1.2.

\subsection{Semeadura in vitro com ácido giberélico}

O teor de água das sementes da planta do município de Bom Jesus foi de $85 \%$, valor bastante superior ao das sementes coletadas em Machadinho, usadas nos experimentos 1.1 e 1.2. As sementes inteiras e os embriões isolados da planta do município de Bom Jesus não germinaram, independentemente da concentração de $\mathrm{GA}_{3}$ no meio de cultivo. Além de não germinar, as sementes estabelecidas inteiras apresentaram uma excepcional proporção de contaminação por microorganismos de origem fúngica e bacteriana (74\%), o que não foi observado em embriões cujos cotilédones foram removidos.

\subsection{Enxertia}

Sete dias após a enxertia de ramos de $P$. willdenovii sobre $P$. venosa, foi iniciada a remoção do saco plástico que cobria o enxerto. Esta remoção foi gradual, iniciando pelo afrouxamento do arame que prendia o plástico na planta. A remoção do mesmo iniciou aos 14 dias: para evitar perda brusca de umidade, fezse um corte em uma das extremidades do plástico e, somente no início da quarta semana, ele foi totalmente removido. Antes mesmo do início da progressiva retirada do plástico, os enxertos apresentaram um declínio, caracterizado por um leve amarelecimento da epiderme, seguido pela desidratação e morte, numa seqüência de eventos bastante similar à incompatibilidade de enxertia registrada em outras espécies (Hartmann \& Kester 1997). Do total de 10 enxertos, não houve sobrevivência após o sexagésimo dia. 


\subsection{Estaquia de ramos}

No período entre o décimo e o décimo quinto dia após a instalação do experimento 4 , ocorreu a queda das folhas das estacas. Este período coincidiu com o início da formação de calos na base das estacas.

Aos 45 dias, foi observada a emissão de brotações nos ápices das estacas de diâmetro menor que $9 \mathrm{~mm}$ (Fig. 1f), e nas gemas laterais das estacas de maior diâmetro. Essas brotações se desenvolveram até atingir 1 a $2 \mathrm{~cm}$ de comprimento aos 60 dias. Entretanto, estas brotações regrediram gradativamente, com uma coloração amarelecida, até a morte de $100 \%$. Nessa ocasião, foram retiradas algumas estacas do substrato para a observação dos calos basais e constatou-se que, assim como as brotações, os calos também estavam morrendo. As brotações regrediram mais lentamente nas estacas de maior diâmetro, permanecendo vivas por, aproximadamente, 30 dias. No entanto, antes de iniciar o amarelecimento, foram selecionadas as melhores brotações e calos, retirados das estacas e submetidos a cultivo in vitro, conforme descrito no item 3.2.

Desta forma, apesar da formação de brotações e de calos basais, não houve enraizamento. Os tecidos das brotações e calogênicos foram destacados das estacas e estabelecidos in vitro, apresentando menor contaminação (12\% para brotações e $40 \%$ para calos) do que tecidos oriundos da planta matriz (100\% de contaminação - exógena e endógena).

\subsection{Propagação vegetativa in vitro a partir de tecidos juvenis}

O potencial morfogênico dos segmentos nodais foi bem maior do que o dos ápices caulinares. Devido à morte ou à baixa indução à organogênese nos ápices caulinares, suas brotações não foram contabilizadas nos experimentos posteriores. Após 42 dias em meio de indução (B), cada segmento nodal apresentou 2,5 $\pm 1,2$ brotações (Fig. 1g).

Em meio de multiplicação $\mathrm{D}$, o número de plantas regeneradas por explante foi significativamente inferior na ausência de BAP em relação aos meios com 0,3; 0,6; 0,9 e 1,2 mg. $1^{-1}$ de BAP $(\operatorname{Pr}>F=<0,001)$. Sem BAP no meio de cultivo, a média foi de $0,5 \pm 0,2$. Os demais tratamentos não diferiram entre si, com média de $0,8 \pm 0,2$ plantas.

Nas etapas de multiplicação e enraizamento, ocorreu morte de plantas sem uma causa identificável, em um processo iniciado pela clorose das folhas, seguido de necrose e morte de toda a planta, enraizada ou não. Somando-se perdas de plantas por contaminação e morte, houve enraizamento de apenas $50 \%$ do total de 129 plantas transferidas para meio E (Fig. 1h). Além disso, houve perda de $15 \%$ das plantas na etapa de aclimatização. Ao final do experimento 3.1, apesar de todas as perdas, foram produzidas 42 plantas a partir de apenas quatro sementes (Fig. 1i).

As plântulas que tiveram o caulículo removido junto aos cotilédones emitiram, continuadamente, duas a três brotações que forneceram explantes com grande potencial morfogênico, em maioria, livres de contaminação. Estas brotações foram subcultivadas até a regeneração de plantas completas.

\subsection{Propagação vegetativa in vitro a partir de tecidos não juvenis}

Não foram bem sucedidas as tentativas de indução de segmentos nodais à organogênese direta in vitro. A primeira causa do insucesso foi o alto grau de contaminação fúngica e bacteriana dos tecidos não juvenis e, a segunda, a oxidação fenólica.

No cultivo de ápices caulinares, não houve indução à organogênese, devido à contaminação de parte dos explantes. Aqueles que não contaminaram, oxidaram em até 15 dias.

Antes de expressarem qualquer tipo de regeneração, os explantes foliares foram tomados por microorganismos. Cinco dias após a inoculação, verificou-se crescimento de micélios de fungos e de uma proliferação bacteriana leitosa e amarelada. 
Brotações e calos emitidos por estacas lenhosas não responderam às tentativas de indução à organogênese e à embriogênese. Nestes tecidos, houve $40 \%$ de contaminação nos explantes de calos e $12 \%$ nos de parte aérea. Os explantes não contaminados permaneceram por 15 a 20 dias com aparente possibilidade de regeneração, porém, em nenhum dos tratamentos houve formação de brotação ou de estrutura embriogênica. Ou seja, brotações e calos de estacas responderam ao cultivo como os demais tecidos não-juvenis.

\section{Discussão}

Poucos autores referiram-se à conservação das espécies nativas do gênero Persea (Barrientos-Pliego \& López-López 1998). Também são escassos os trabalhos visando à pesquisa em propagação e à produção de mudas destas plantas.

Por se tratar de uma frutífera, protocolos de propagação estão disponíveis apenas para $P$. americana, mesmo assim, requerendo a superação de obstáculos, principalmente a restrição do potencial morfogênico aos tecidos juvenis ou rejuvenescidos (Von Aderkas \& Bonga 2000). Além disso, a contaminação de origem endógena e a oxidação fenólica dos explantes são fatores críticos para a viabilidade dos protocolos (Biasi et al. 1994; Rodrigues et al. 1996).

A variabilidade genética disponível para o melhorista na espécie $P$. americana provém oportunidades quase ilimitadas para a seleção de excelentes cultivares copa. Contudo, a falta de bons porta-enxertos é um problema sério, principalmente no que se refere à suscetibilidade aos fungos de solo (PliegoAlfaro \& Bergh 1992). A resistência presente nas espécies do subgênero Eriodaphne, sexualmente incompatível com $P$. americana, poderá ser empregada na seleção de novos porta-enxertos, a partir de estudos que iniciam justamente pela propagação destas espécies.

Por meio desta seqüência de experimentos, conduzida ao longo de 41 meses, foi possível fazer o primeiro registro da resposta de $P$. willdenovii às estratégias mais comuns de propagação.

\section{Propagação sexuada}

$\mathrm{Na}$ família das lauráceas, há várias espécies com sementes intolerantes à dessecação. Por esta característica, associada à baixa longevidade, suas sementes foram classificadas como recalcitrantes, de acordo com Roberts (1973). As sementes de muitas espécies recalcitrantes germinam rapidamente após a dispersão, ou ainda, na planta matriz. Em contraste, há espécies cujas sementes requerem um tratamento de frio para maximizar a germinação, como Cinnamomum subavenicum (Vozzo 2002).

Davide et al. (2003) testaram a capacidade de armazenamento de sementes de quatro espécies clímax, dos gêneros Cryptocarya, Nectandra, Ocotea e Persea. Em condições iniciais de teor de água (50\% para $C$. aschersoniana, $38,3 \%$ para $N$. nitidula, 51,6\% para $O$. odorifera e $53 \%$ para P. willdenovii), a germinação foi de 29,20, 25 e $0 \%$, respectivamente. $\mathrm{O}$ armazenamento dessas sementes por 90 dias a $5^{\circ} \mathrm{C}$ elevou significativamente o percentual de germinação para $C$. aschersoniana (78\%), N. nitidula (40\%) e $P$. willdenovii (73\%), enquanto o teor de água permaneceu elevado $(46,4,33,7,48 \%$, respectivamente). Já para $O$. odorífera, após o armazenamento a $5^{\circ} \mathrm{C}$ não ocorreu germinação. Após a dessecação, em que o teor de água diminuiu para 8,10,10 e 20\%, para C. aschersoniana, $N$. nitidula, O. odorifera e $P$. willdenovii, respectivamente, não houve germinação. Possivelmente o período de avaliação (30 dias) tenha sido insuficiente, o que explica a não ocorrência de germinação das sementes recém coletadas de $P$. willdenovii estudadas por Davide et al. (2003). Sementes de algumas espécies recalcitrantes, como $P$. kusanoi, necessitam de um período de maturação após a coleta dos frutos, antes de serem beneficiadas (Vozzo 2002). Enquadramse como dormentes as espécies cuja germinação inicia em um prazo maior que 
quatro semanas após a semeadura, conforme classificação de Baskin \& Baskin (1998). Em espécies arbóreas da flora brasileira que apresentam algum tipo de dormência, no grupo das espécies não pioneiras, predomina a de natureza endógena (Ferreira \& Borguetti 2004).

No experimento 1.1 , a emergência ocorreu no período de 34 a 100 dias após a semeadura em areia. Também no experimento 1.2 , as primeiras plântulas começaram a emergir após 42 dias da semeadura. Este comportamento sustenta a hipótese de ser a dormência a causa do requerimento de um período maior para o início da germinação após a coleta. Davide et al. (2003) sugeriram a presença de dormência endógena do tipo morfológica (embrião imaturo). No entanto, foi constatado que os embriões estabelecidos no experimento 1.4 estavam perfeitamente desenvolvidos, o que sugere dormência endógena de natureza fisiológica, tal como foi registrada para outras espécies recalcitrantes de lauráceas, como O. puberula, O. odorifera, O. porosa e N. lanceolata (Carvalho 1994; Randi 1982; Ferreira \& Borghetti 2004).

$\mathrm{O}$ regime térmico não influenciou a germinação em areia, indicando que a dormência endógena presente nas sementes, de provável natureza fisiológica, não é superada pelas temperaturas testadas. Por outro lado, é possível que a diferença entre o percentual de emergência dentro de germinadores, sob condições térmicas controladas, e o percentual de emergência em casa de vegetação, esteja relacionada à variação térmica na casa de vegetação. A amplitude térmica pode ter influenciado o processo de germinação, pois, aproximadamente, $70 \%$ do total de emergência aconteceu quando a temperatura média do ambiente estava abaixo de $15^{\circ} \mathrm{C}$ (entre 75 e 130 dias após a semeadura). É provável que seja necessário um período de baixas temperaturas, logo após a semeadura, para superar a dormência das sementes de $P$. willdenovii. Este resultado confirma a observação de Davide et al. (2003), em que $73 \%$ das sementes germinaram após armazenamento a $5^{\circ} \mathrm{C}$.

Nas condições propostas, um baixo percentual de sementes da planta de Machadinho (16 a 51\%) germinou. Por outro lado, as sementes do município de Bom Jesus não germinaram in vitro. $\mathrm{O}$ elevado teor de água destas sementes serviu como indicativo da imaturidade dos frutos no momento da coleta. Em comparação, as sementes coletadas em Machadinho apresentavam características típicas de maturação, como polpa macia e testa lignificada, com teor de água das sementes bem inferior.

Dentre os fatores ambientais que atuam sobre a eficiência da germinação, a disponibilidade e a qualidade da água, do ar e dos nutrientes são fatores importantes e que dependem muito do substrato utilizado como leito de semeadura. De acordo com Baskin \& Baskin (1998), nitratos e nitritos são efetivos na superação de dormência e/ou na promoção da germinação de muitas sementes sensíveis à luz. Estes autores relataram que nitratos de potássio, sódio, amônio e nitritos promoveram a germinação de sementes de Capsella bursapastoris em temperaturas alternadas, porém, não em temperaturas constantes. $\mathrm{O}$ mesmo ocorreu com Polygonon monspeliensis em presença de nitrato de potássio. As características físicas do substrato devem ser adequadas, inclusive, ao tamanho do recipiente. De acordo com Kämpf (2000), para recipientes pequenos, como "plugs", a densidade do substrato deve ser de, no máximo, $300 \mathrm{~kg} \mathrm{~m}^{-3}$. Nesta condição, o espaço de aeração é elevado e facilita a drenagem, uma vez que a baixa altura do recipiente impede que a ação da gravidade elimine o excesso de água da irrigação. No entanto, substratos muito porosos podem secar rapidamente, além de possuírem área de contato reduzida, dificultando a hidratação das sementes.

Em um experimento para a aclimatização de P. venosa, Rodrigues \& Fior (2000) constataram que a constituição do substrato influenciou significativamente no percentual de 
sobrevivência de plantas micropropagadas. No substrato formado por iguais proporções volumétricas de casca de arroz carbonizada, areia fina e turfa preta, a sobrevivência foi significativamente menor e insatisfatória: $45 \%$ de sobreviventes, contra 68 e $67 \%$, nos substratos casca de arroz carbonizada e casca de arroz carbonizada mais areia (1:1), respectivamente. É possível que o maior percentual de casca de arroz carbonizada no substrato tenha favorecido a sobrevivência à aclimatização devido à maior aeração.

$\mathrm{Na}$ semeadura de $P$. willdenovii em três substratos, a emergência inicial mais rápida em composto orgânico pode ter ocorrido em função da maior densidade do substrato, favorecendo o contato das partículas com a semente, e, com isso, facilitando a transferência de água. Aos 200 dias, o substrato não interferiu no percentual de emergência de $P$. willdenovii, mas o desenvolvimento das mudas foi significativamente superior em pó-de-coco Golden Mix PM ${ }^{\circledR}$. A altura significativamente maior das plantas em PC pode estar diretamente relacionada às menores densidade e salinidade deste substrato, favorecendo o desenvolvimento do sistema radicular e, conseqüentemente, da parte aérea.

A germinação de sementes in vitro requer mais recursos e mão de obra, porém, em $P$. venosa, foi uma estratégia valiosa para garantir o bom aproveitamento de um pequeno número de sementes e para prevenir a perda de sementes de frutos colhidos imaturos. Este recurso permitiu a germinação de $100 \%$ das sementes de frutos colhidos maduros e de 55\% das sementes de frutos colhidos imaturos (Rodrigues et al. 1998). Além disso, as plântulas obtidas da germinação in vitro podem ser fracionadas e subcultivadas, visando à organogênese direta, de modo que um só embrião origina grande número de plantas.

A germinação in vitro de $P$. willdenovii não correspondeu ao que foi observado em $P$. venosa por Rodrigues et al. (1998). Porém, esta resposta pode estar relacionada ao requerimento de um período de baixas temperaturas, já indicado no experimento 1.1 e 1.2. Apesar disso, a germinação de sementes in vitro foi a única estratégia que viabilizou a propagação clonal de $P$. willdenovii. O estabelecimento de embriões isolados foi ainda mais vantajoso que o da semente inteira, pois preveniu a contaminação. Contudo, é necessário conhecer as condições de cultivo que permitem a regeneração de plantas a partir de embriões.

Em $P$. americana, é possível regenerar plantas in vitro a partir de embriões imaturos destacados dos cotilédones. Este recurso foi usado para prevenir a perda de embriões por abscisão dos frutos (Skene \& Barlass, 1983). Nesta técnica, a idade do embrião foi um fator crítico para o desenvolvimento, pois somente embriões com mais de seis semanas apresentaram índices satisfatórios de sobrevivência in vitro. Skene \& Barlass (1983) utilizaram o meio MS líquido diluído e acrescido de 2,2 $\mathrm{mM}$ de BAP. Neste processo, os cotilédones foram removidos, para favorecer o crescimento do embrião. O enraizamento dos embriões obtidos por Skene \& Barlass (1983) foi baixo, por isso, as brotações foram enxertadas. No entanto, embriões obtidos de sementes maduras por Pliego-Alfaro (1988) apresentaram $100 \%$ de enraizamento.

\section{Propagação vegetativa}

A enxertia intraespecífica por garfagem é amplamente empregada para a produção de mudas comerciais de P. americana (Biasi, 1995). As enxertias interespecífica e intersubgenérica ainda não foram estabelecidas para a propagação de plantas do gênero Persea, porém, foi confirmada experimentalmente a compatibilidade entre $P$. americana e algumas espécies do subgênero Eriodaphne: P. nubigena, P. steyermarkii, $P$. schiedeana, $P$. floccosa e $P$. longipes (Pliego-Alfaro \& Bergh 1992; BarrientosPliego \& López-López 1998).

A compatibilidade de enxertia entre $P$. willdenovii e $P$. venosa ainda não havia sido testada. Neste caso, o declínio progressivo 
do enxerto após a quarta semana pode ser atribuído, tanto à incompatibilidade histológica, ainda que as duas espécies pertençam ao mesmo subgênero, quanto às condições ambientais em que a enxertia foi executada. Este resultado inicial negativo não deve ser considerado como definitivo. A histocompatibilidade interespecífica é muito importante para a viabilização do emprego de germoplasma nativo como fonte de variabilidade para o melhoramento de portaenxertos de $P$. americana. Por isso, futuros trabalhos devem testar combinações genotípicas e técnicas de enxertia e agregar recursos adicionais para a proteção dos tecidos.

Apesar da importância da enxertia na geração de mudas, a obtenção de portaenxertos clonais é o fator que demanda maior atenção dos propagadores de plantas. A estaquia de ramos é uma técnica de propagação econômica e eficiente para inúmeras espécies lenhosas (Hartmann \& Kester 1997). Porém, o sucesso da estaquia a partir de tecidos não-juvenis de espécies do gênero Persea é restrito ao emprego de tecidos estiolados.

Em P. americana, a propagação clonal a partir de tecidos não-juvenis é viabilizada por variações da técnica de Frolich (1961) e Frolich \& Platt (1971-72), muito bem descritas por Biasi (1995). Neste caso, os tecidos são induzidos à brotação no escuro e os ramos estiolados são postos em contato com o substrato de enraizamento. As plantas resultantes do processo são, então, utilizadas como porta-enxerto.

O custo adicional desta técnica é compensado em $P$. americana, porque o emprego de porta-enxertos segregantes é o principal problema fitotécnico dos pomares: diferentes graus de tolerância às fontes de estresse ambiental desencadeiam desuniformidade produtiva. A constituição de pomares clonais, com genótipos selecionados especificamente para porta-enxerto e para copa, supera este obstáculo.
A estaquia de $P$. willdenovii em casca de arroz carbonizada apresentou a mesma resposta registrada em $P$. venosa (Rodrigues et al. 1998): esporadicamente, os ramos de maior diâmetro formam brotações apicais e calos basais, mas não há formação de raízes. Assim, é necessário testar variações das técnicas de enraizamento de ramos estiolados, para viabilizar a propagação de $P$. willdenovii por estaquia.

Contudo, ainda que a estaquia de ramos estiolados viabilize o enraizamento para a obtenção de plantas de $P$. willdenovii, esta técnica não permitiria a limpeza clonal. Ou seja, o desenvolvimento de técnicas de cultivo in vitro desta espécie é indispensável.

Em uma ampla pesquisa bibliográfica do gênero Persea, foram encontrados trabalhos sobre o cultivo in vitro apenas com as espécies P. americana, $P$. indica (Nell et al. 1983; Rodrigues et al. 2001) e P. venosa (Rodrigues et al. 1998).

O cultivo in vitro de $P$. americana, ainda está limitado à neomorfogênese de tecidos juvenis ou rejuvenescidos. A indução à embriogênese é feita em tecidos zigóticos extraídos de frutos imaturos (Pliego-Alfaro \& Murashige 1988; Witjaksono et al. 1998). A indução à organogênese é feita a partir de brotações fracionadas da plântula recémgerminada (de la Vinã et al. 1999) ou de brotações rejuvenescidas por estiolamento (Biasi et al. 1994; Rodrigues et al. 1997), corte basal da planta adulta (Barceló-Muñoz et al. 1999) e enxertia (de la Vinã et al. 2001).

A organogênese de múltiplas e sucessivas brotações da semente germinada in vitro permitiu a propagação clonal de $P$. willdenovii. Esta mesma estratégia foi registrada em P. venosa por Rodrigues et al. (1998) e permitiu a produção de dezenas de plantas clonais a partir de um só embrião.

Todas as técnicas de propagação vegetativa testadas apresentaram resultados insatisfatórios, exceto a propagação in vitro, a partir dos tecidos juvenis. Entretanto, foram 
encontradas limitações que demandarão atenção especial: o aparecimento de contaminação de origem endógena em parte do material, mesmo após subcultivo; necrose e clorose de folhas in vitro, culminando na morte de algumas plantas; percentual de enraizamento insatisfatório; e perda de plantas na aclimatização, mesmo sob nebulização intermitente. Além disso, foram observadas diferenças no potencial morfogênico entre plântulas de diferentes sementes, ainda que o material tenha origem na mesma planta matriz.

De modo geral, as respostas ao cultivo in vitro de $P$. willdenovii são similares às de $P$. americana, $P$. indica e $P$. venosa. O cultivo de tecidos não-juvenis não obtém sucesso, tanto pelo baixo potencial morfogênico, quanto também pela ocorrência de contaminação de origem endógena e de oxidação fenólica. Isso indica que as mesmas estratégias para rejuvenescimento de explantes de $P$. americana devem ser testadas em $P$. willdenovii. No caso de $P$. americana, o emprego de brotações emitidas de matrizes mantidas por 12 semanas em câmara escura e vedada, com aplicação semanal de antibióticos, permitiu o estabelecimento de cultivos (Rodrigues et al. 1997), porém, o potencial morfogênico não foi pleno.

O emprego predominante de tecidos do zigoto e da plântula, como fonte de explantes, gera lotes de mudas constituídos de clones dos embriões originais, cujo desempenho vegetativo ainda é desconhecido. O uso destes tecidos atende satisfatoriamente ao objetivo de preservação de germoplasma, porém, não permite a propagação massal de um indivíduo adulto em especial. Assim, não podem ser preservados genótipos que apresentem combinações de características especialmente vantajosas ao emprego fitoterápico, ou ainda visando ao melhoramento genético.

Em $P$. americana, foi proposta uma alternativa para esta limitação: a planta adulta é cortada na base e as brotações são coletadas e estabelecidas in vitro, pois estas brotações têm características juvenis (Barceló-Muñoz et al. 1999). No trabalho com plantas matrizes nativas, entretanto, esta estratégia é inviável. Mesmo a remoção de pequenas partes das raras plantas de $P$. willdenovii encontradas no estado do Rio Grande do Sul deve ser comedida, pois o seu desenvolvimento vegetativo já foi intensamente prejudicado, principalmente pela depredação.

Em algumas espécies perenes, como Hevea brasiliensis (Michaux-Ferriére et al. 1992), Vitis rupestris (Altamura et al. 1992) e Manihot esculenta (Woodward \& PuontiKaerlas 2001), a propagação in vitro foi viabilizada por indução à embriogênese a partir de peças florais. Esta é uma alternativa promissora para a propagação clonal das espécies do gênero Persea, pois empregaria um pequeno volume de material vegetal para atender, tanto ao objetivo de preservação da variabilidade genética dos exemplares nativos ameaçados, quanto ao de produção de clones em escala comercial. Além disso, a embriogênese induzida in vitro tem grande potencial para disponibilizar variabilidade para o melhoramento genético das plantas cultivadas, permitindo a indução de mutações (de la Viña et al. 2001; Witjaksono \& Litz 2004), o cultivo de protoplastos isolados (Liendo et al. 1997; Witjaksono et al. 1998) e a transformação genética (Cruz-Hernandez et al. 1998; Gomez-Lim \& Litz 2004).

A fusão de protoplastos, especialmente gametofíticos, é de especial interesse para o aproveitamento do germoplasma silvestre, e, neste caso, pode viabilizar a hibridação in vitro entre $P$. americana e espécies do subgênero Eriodaphne. Neste caso, seria possível desenvolver genótipos que conciliassem a histocompatibilidade com $P$. americana e a resistência ao fungo $P$. cinnamomi, para emprego como porta-enxerto. Porém, inúmeras etapas deverão ser vencidas até que estes recursos estejam disponíveis.

Mais do que observações iniciais inéditas, este trabalho apresenta um novo 
problema de pesquisa para a preservação das espécies ameaçadas da flora brasileira. $\mathrm{O}$ estudo das espécies nativas do gênero Persea está em uma condição inicial. Até mesmo questões taxonômicas ainda requerem esclarecimentos.

Até o presente, através dos trabalhos visando à propagação de $P$. willdenovii, o JB/ FZB-RS gerou 300 novas mudas a partir do material coletado de apenas duas plantas. As informações obtidas neste trabalho subsidiarão futuros projetos para a apropriação do patrimônio genético e para a contenção do iminente processo de extinção desta espécie no Estado. A perspectiva do emprego de germoplasma nativo para resolver problemas da humanidade é apenas uma das justificativas para investimentos na pesquisa e preservação de $P$. willdenovii.

\section{Agradecimentos}

Os autores agradecem a Rosana $\mathrm{M}$. Senna (MCN/FZB-RS), Andréia M. Carneiro (JB/FZB-RS) e Marcos E. G. Sobral (Instituto de Ciências Biológicas/UFMG) pelas informações quanto à denominação da espécie. Às biólogas Anaíse C. Calil e Laline Carneiro Tôrres e aos acadêmicos Denise Barbosa Ramos, Ângela C. Busnello, Pedro C. S. Shäffer e Diana S. Bertoglio, pela participação em diferentes etapas deste trabalho. Às Prefeituras Municipais de Machadinho e Marcelino Ramos, RS. Ao Sr. Fernando Cassol (Parque Quinto Rancho, Marcelino Ramos). Em memória, ao Sr. Eduardo Vecchi (Secretário de Turismo de Marcelino Ramos).

\section{REFERÊNCIAS BIBLIOGRÁFICAS}

Adeyemi, O. O.; Okpo, S. O. \& Ogunti, O. O. 2002. Analgesic and anti-inflammatory effects of the aqueous extract of leaves of Persea americana Mill. (Lauraceae). Fitoterapia 73 (5): 375-380.

Altamura, M. M.; Cersosimo, A.; Majoli, C. \& Crespan, M. 1992. Histological study of embryogenesis and organogenesis from anthers of Vitis rupestris du Lot cultured in vitro. Protoplasma 171: 134-141.

Barceló-Muñoz, A.; Encina, C. L.; SimónPérez, E. \& Pliego-Alfaro, F. 1999. Micropropagation of adult avocado. Plant Cell Tissue and Organ Culture 58: 11-17.

Barrientos-Pliego, A. F. \& López-López, L. 1998. Historia y genetica del aguacate. Fundación Salvador Sánchez Colin CICTAMEX S.C. Coatepec Harinas. Disponível em: <http://www.avocadosource. c o m / J o u rnals / C I C T A MEX/ C I C T A M E X_1998-2001/ CICTAMEX_1998-2001_PG_100121.pdf>. Acesso em 18 abr. 2005

Baskin, C. C. \& Baskin, J. M. 1998. Seeds: ecology, biogeography and evolution of dormancy and germination. Academic Press, San Diego, 666p.

Biasi, L. A. 1995. Propagação do abacateiro. Agropecuária Catarinense 8(3): 29-31.

; Koller, O. C. \& Kämpf A. N. 1994. Micropropagação do abacateiro Ouro Verde a partir de segmentos nodais. Pesquisa Agropecuária Brasileira 29(7): 1051-1058.

Brasil - Ministério da Agricultura e Reforma Agrária. 1992. Regras para análise de sementes. SNDA/DNDV/CLAV, Brasília, $365 \mathrm{p}$.

Caballero-George, C.; Vanderheyden, P. M. L.; Solis, P. N.; Pieters, L.; Shahat, A. A.; Gupta, M. P.; Vauquelin, G. \& Vlietinck, A. J. 2001. Biological screening of selected medicinal Panamanian plants by radioligand-binding techniques. Phytomedicine 8(1): 59-70.

Carvalho, P. E. R. 1994. Espécies florestais brasileiras. Recomendações silviculturais, potencialidades e uso da madeira. Empresa Brasileira de Pesquisa Agropecuária, EMBRAPA-CNPF, Colombo, 640p.

Cptec. Centro de Previsão de Tempo e Estudos Climáticos. 2003. Citação de banco de dados on line. Cachoeira Paulista. 
Disponível em: <http://www. cptec. inpe. br/ dados_observados > Acesso em: 01 jul 2004

Cruz-Hernandez, A.; Witjaksono; Litz, R. E. \& Lim, M. G. 1998. Agrobacterium tumefaciens - mediated transformation of embryogenic avocado cultures and regeneration of somatic embryos. Plant Cell Reports 17(6-7): 497-503.

Davide, A. C.; Carvalho, L. R.; Carvalho, M. L. M. \& Guimarães, R. M. 2003. Classificação fisiológica de sementes de espécies florestais pertencentes à família Lauraceae quanto à capacidade de armazenamento. Cerne 9(1): 29-36.

De La Viña, G.; Barceló-Muñoz, A. \& PliegoAlfaro, F. 2001. Effect of culture media in irradiance level on growth and morphology of Persea americana Mill. microcuttings. Plant Cell Tissue and Organ Culture 65: 229-237.

; Pliego-Alfaro, F.; Driscoll, S. P.; Mitchell, V. J.; Parry, M. A. \& Lawlor, D. W. 1999. Effects of CO2 and sugars on photosynthesis and composition of avocado leaves grown in vitro. Plant Physiology Biochemistry 37(7-8): 587-595.

Ferreira, A. G. \& Borghetti, F. 2004. Germinação: do básico ao aplicado. Artmed, Porto Alegre, 323p.

Fraga, B. M.; Terrero, D.; Gutierrez, C. \& Gonzalez-Coloma, A. 2001. A Minor diterpenes from Persea indica: their antifeedant activity. Phytochemistry 56(4): 315-320.

Frolich, E. F. 1961. Etiolation and the rooting of cutting. Proceedings of International Plant Propagators Society 11: 277-283.

\& Platt, R. G. 1971-72. Use of the etiolation technique in rooting avocado cuttings. California Avocado Society Yearbook 55: 97-109.

Gallagher, A. M.; Flatt, P. R.; Duffy, G. \& Abdel-Wahab, Y. H. A. 2003. The effects of traditional antidiabetic plants on in vitro glucose diffusion. Nutrition Research 23(3): 413-424.

Gamborg, O. L.; Miller, R. A. \& Ojima, K. 1968. Nutrient requirements of suspensions cultures of soybean root cells. Experimental Cell Research 50: 151-158.

Gomez-Lim, M. A. \& Litz, R. E. 2004. Genetic transformation of perennial tropical fruits. In Vitro Cellular \& Developmental Biology-Plant 40(5): 442449.

Hartmann, H. T. \& Kester, D. E. 1997. Propagación de Plantas. Princípios e Práticas. Compañia Editorial Continental, México, 760p.

Jacomino, A. P.; Minami, K.; Kluge, R. A. \& Kishino, A. Y. 2000. Methods of graft protection in the production of mango, avocado and macadamia nut nursery trees. Pesquisa Agropecuária Brasileira 35(10): 1985-1990.

Kämpf, A. N. 2000. Produção Comercial de Plantas Ornamentais. Livraria e Editora Agropecuária, Porto Alegre, 254p.

Kostermans, A. J. G. H. 1969. Revision of Lauraceae II.Reinwardtia 7: 511.

Liendo, A.; Villegas, L. \& Alvarez, R. C. 1997. Isolation, purification and characterization of protoplasts from wild and cultivated species of Persea. Plant Physiology 114(3 supplement): 1617.

Michaux-Ferriére, N.; Grout, H. \& Carron, M. P. 1992. Origin and ontogenesis of somatic embryos in Hevea brasiliensis (Euphorbiaeae). American Journal of Botany 79(2): 174-180.

Murashige, T. \& Skoog, F. 1962. A revised medium for rapid growth and bioassays with tobacco tissue cultures. Physiologia Plantarum 15: 473-497.

Nell, D. D.; Kotzé, J. M. \& Snyman, C. P. 1983. In vitro propagation of Persea indica. Yearbook South African Avocado Growers Association 6: 92. 
Pedralli, G. 1983. A família Lauraceae Lindley. Dissertação de Mestrado. Universidade Federal do Rio Grande do Sul, Porto Alegre.

Pliego-Alfaro, F. 1988. Development of an in vitro rooting bioassay using juvenilephase stem cuttings of Persea americana Mill. The Journal of Horticultural Science 63(2): 295-301.

\& Bergh, B. O. 1992. Avocado. In: Hammerschlag, F. A. \& Litz, R. E. (eds.). Biotechnology of fruit crops. CAB International, Wallingford. Pp. 323334.

\& Murashige, T. 1988. Somatic embryogenesis in avocado (Persea americana Mill.) in vitro. Plant Cell Tissue and Organ Culture 12: 61-66.

Quinet, A. \& Andreata, R. H. P. 2002. Lauraceae Jussieu na Reserva Ecológica de Macaé de Cima, Município de Nova Friburgo, Rio de Janeiro, Brasil. Rodriguesia 53(82): 59-121.

Randi, A. M. 1982. Estudo preliminar sobre inibidores de germinação em frutos de Miconia cinnamomifolia e Ocotea puberula. In: Congresso Nacional de Essências Nativas. Anais... Instituto Florestal, São Paulo. Pp. 238-242.

Reitz, R.; Klein, R. M. \& Reis, A. 1988. Projeto Madeira do Rio Grande do Sul. Herbário Barbosa Rodrigues, Porto Alegre, 526p.

Röber, R. \& Schaller, K. 1985. Pflanzenernährung in Gartenbau. Stuttgart, Ulmer, 352p.

Roberts, E. H. 1973. Predicting the storage life of seeds. Seed Science and Technology 1(4): 499-514.

Rodrigues, A. P.; Sergio, P. M.; Teixeira, M. R. \& Pais, M. S. 2001. In vitro break of dormancy of axillary buds from woody species (Persea indica and Arbutus unedo) by sectioning with a laser beam. Plant Science 161(1): 173-178.
Rodrigues, L. R.; Bastianel, M.; Dornelles, A. L. C. \& Koller, O. C. 1996. Técnicas de asepsia en la micropropagación del aguacate (Persea americana Mill.). Proceedings of the Interamerican Society for Tropical Horticulture 40: 195-199.

\& Fior, C. S. 2000. Substrato para aclimatização ex vitro de canela-sebo (Persea venosa Nees \& Martius ex Nees). In: Kämpf, A. N. \& Fermino, M. H. (eds.). Substratos para plantas: a base da produção vegetal em recipientes. Genesis, Porto Alegre. Pp. 241-248.

; Fior, C. S. \& Dornelles, A. L. C. 1997. Obtenção de explantes viáveis e regeneração na micropropagação do abacateiro (Persea americana Mill.). In: 2 Encontro Brasileiro de Biotecnologia Vegetal, Gramado. Encontro Brasileiro de Biotecnologia Vegetal - Programa e Resumos. Vol. 2. REDBIO, Porto Alegre, p. 87.

; Fior, C. S.; Leonhardt, C.; Silva, L. C. \& Nilson, A. D. 1998. Ensaios com o cultivo in vitro de explantes nodais de canela-sebo (Persea venosa Nees \& Martius ex Nees). Iheringia 50: 99-112.

Scora, R. W. \& Scora, P. E. 2000. Essential oils of Persea subgenus Persea (Lauraceae) Journal of Essential Oil Research 12(6): 709-713.

Silva, J. B. C. \& Nakagawa, J. 1995. Estudos de fórmulas para cálculo de germinação. Informativo ABRATES 5(1): 62-73.

Skene, K. G. M. \& Barlass, M. 1983. In vitro culture of abcissed immature avocado embryos. Annals of Botany 52: 667-672.

Von Aderkas, P. \& Bonga, J. M. 2000. Influencing micropropagation and somatic embryogenesis in mature trees by manipulation of phase change, stress and culture environment. Tree Physiology 20: 921-928.

Vozzo, J. A. 2002. Tropical tree seed manual. United States Departament of Agriculture, Washington, 899p. 
Witjaksono, N. \& Litz, R. E. 2004. Effect of gamma irradiation on embryogenic avocado cultures and somatic embryo development. Plant Cell Tissue and Organ Culture 77: 139-147.

; Litz, R. E. \& Grosser, J. W. 1998. Isolation, culture and regeneration of avocado (Persea americana Mill.) protoplasts. Plant Cell Reports 18: 235242.

Woodward, B. \& Puonti-Kaerlas, J. 2001. Somatic embryogenesis from floral tissue of cassava (Manihot esculenta Crantz). Euphytica 120: 1-6. 